\section{Matteo Bassetti Garyfallia Poulakou Helen Giamarellou}

\title{
Is there a future for tigecycline?
}

Received: 9 May 2014

Accepted: 13 May 2014

Published online: 29 May 2014

(C) Springer-Verlag Berlin Heidelberg and ESICM 2014

M. Bassetti

Infectious Diseases Division, Santa Maria Misericordia Hospital, Udine, Italy

\section{G. Poulakou}

4th Department of Internal Medicine, Athens University School of Medicine, Attiko University General Hospital, Athens, Greece

H. Giamarellou

Athens University Medical School and 6th Department of Internal Medicine, Hygeia General Hospital, Athens, Greece

M. Bassetti (四)

Clinica Malattie Infettive, Azienda Ospedaliera Universitaria Santa Maria della Misericordia, Piazzale Santa Maria della Misericordia 15, 33100 Udine, Italy

e-mail: mattba@tin.it

Tel.: +390432559355

In 2010 and 2013, the US Food and Drug Administration (FDA) reported an increased risk of mortality associated with tigecycline use in comparison with other drugs in the treatment of serious infections. The analysis used a pooled group of randomized clinical trials including hospital-acquired pneumonia (HAP) and ventilator-associated pneumonia (VAP), complicated skin and soft tissue infections (cSSTI), complicated intra-abdominal infections (cIAI), and diabetic foot infections [1, 2]. On the basis of the pooled data analysis, the FDA recommended that alternatives to tigecycline should be considered in patients with severe infections. After the
FDA warning several meta-analysis were published; obviously using different methodologies and selecting different studies. Yahav et al. [3] meta-analysis reported statistically higher all-cause 30-day mortality in the tigecycline arms. On the other hand, Cai et al. [4] found no difference in all-cause mortality and drug-related mortality between tigecycline and the comparators, whereas Tasina et al. [5] demonstrated reduced clinical efficacy and increased mortality for tigecycline, but the difference was not statistically significant. The FDA alert has been further jeopardized by two more studies. McGovern et al. [6] performed an all-cause mortality analysis by use of logistic regression and classification and regression tree analyses on study-level and patient-level data in an effort to find a reason for the increase in mortality. Deaths were attributed to infections or underlying co-morbidities and not to tigecycline. Subsequently, Vardakas et al. [7] separately analyzed studies involving infections for which tigecycline has approval and reported no statistical difference in clinical efficacy and no significant increase in mortality. On the other hand, analyzed data from non-approved indications showed that the tigecycline arm was statistically less effective. Finally, meta-analyses of study-level data suggested decreased clinical efficacy as a possible explanation for the demonstrated imbalance in mortality $[3,8]$.

In their interesting and welcome article published in the current issue of intensive care medicine, Montravers et al. [9] conclude that tigecycline success rates in patients in ICU with severe infections appear comparable to those reported with other antibiotics; the overall success rate was $60 \%$ at the end of treatment, and $53 \%$ 7 days later. Furthermore, they report a survival rate of $85 \%$ at day 28 . Historically, clinical trials concerning management of critically ill and particularly ICU-admitted patients with tigecycline are limited. A few large observational studies have been set up to determine the outcomes of ICU tigecycline-treated patients in clinical practice and a recent multicenter European surveillance study encompassing 1,782 patients (56\% from ICU), who 


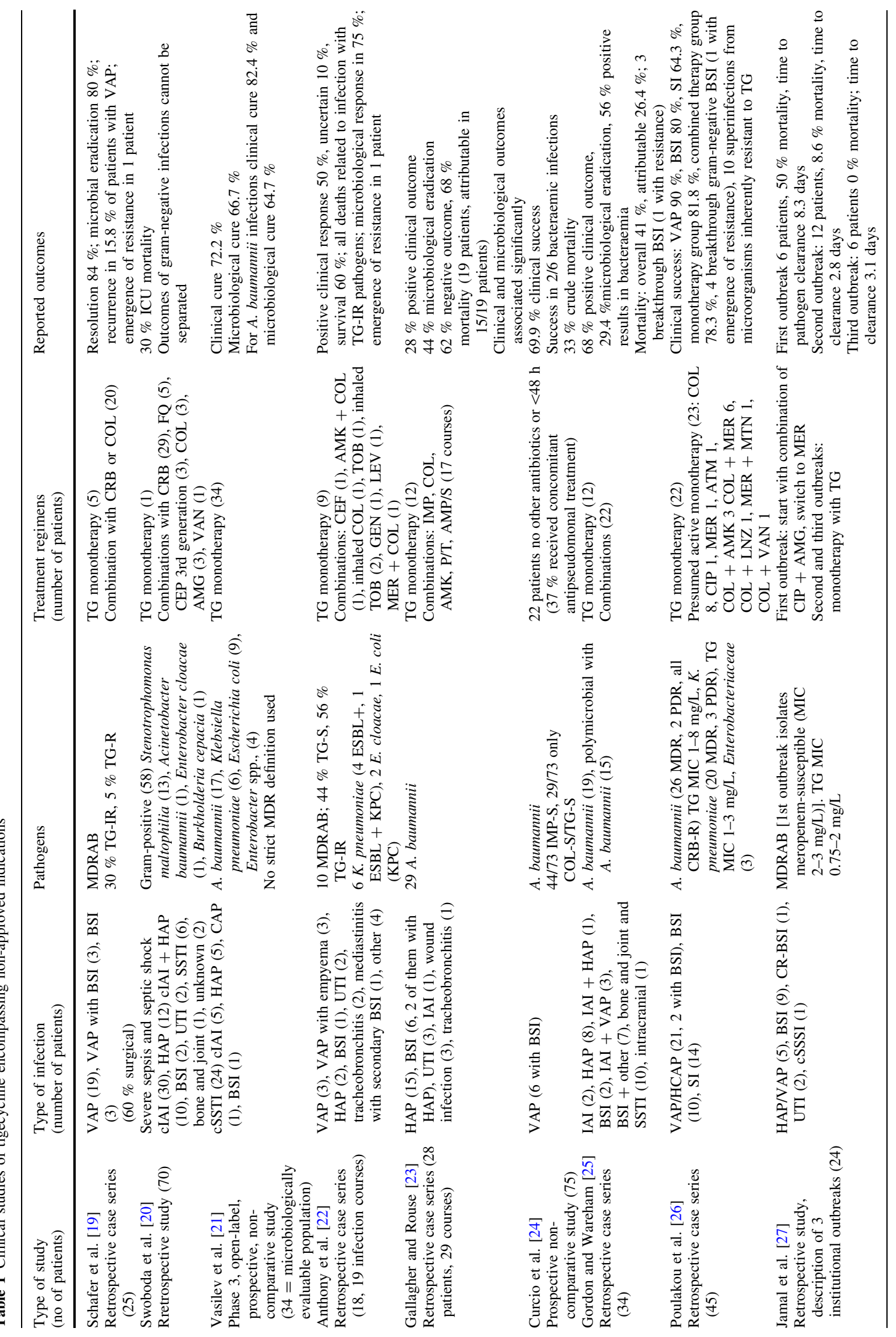




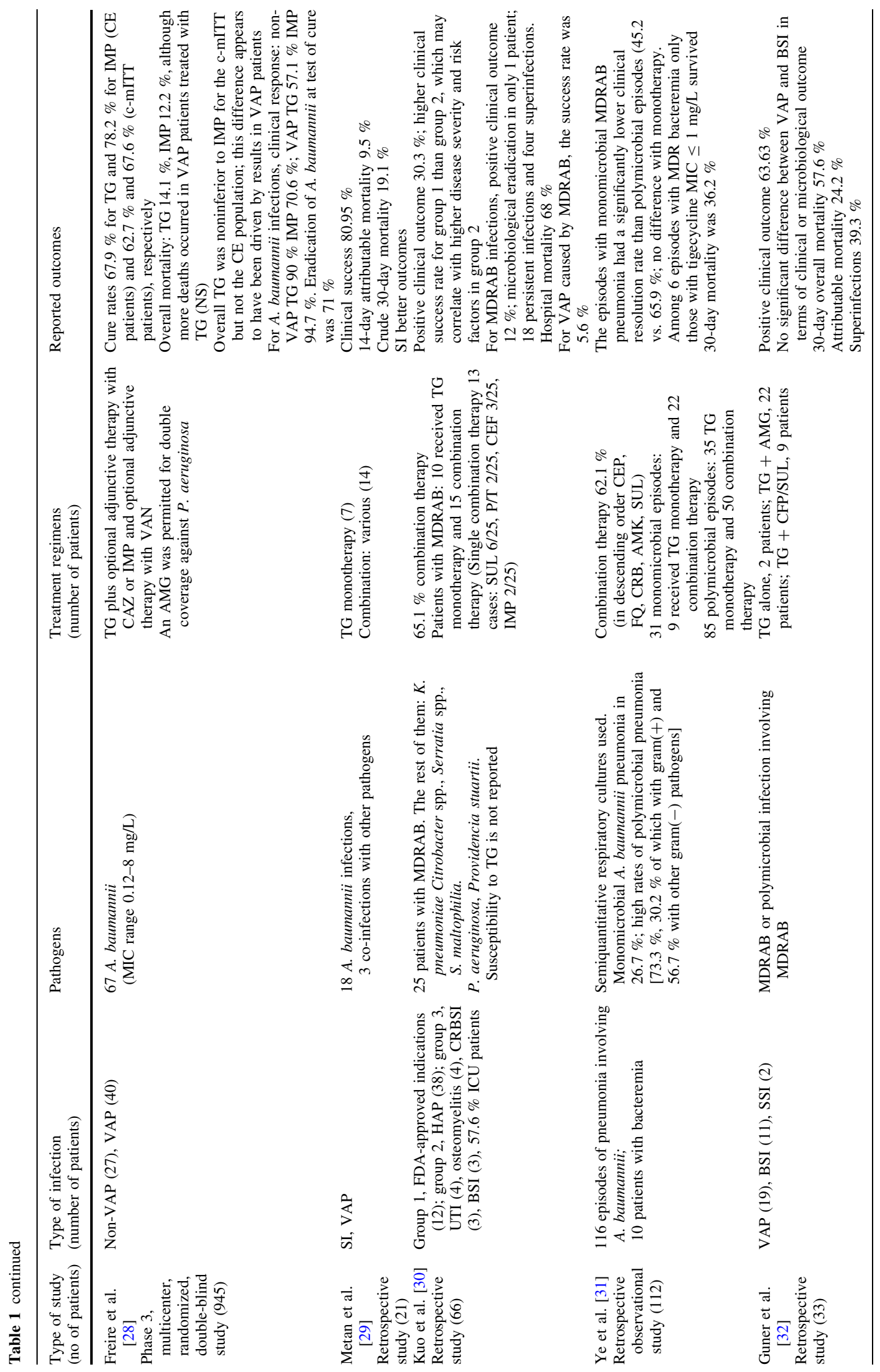




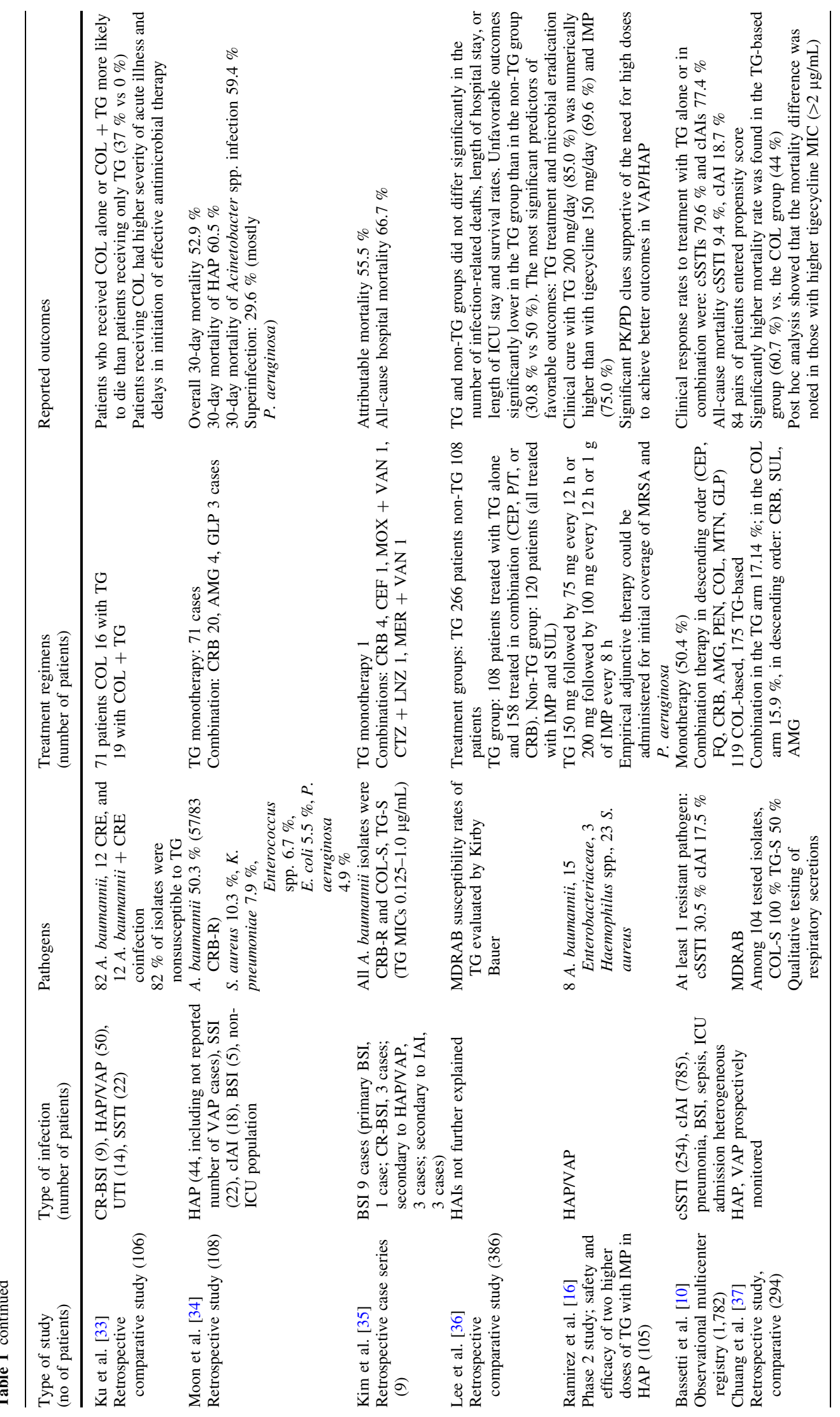




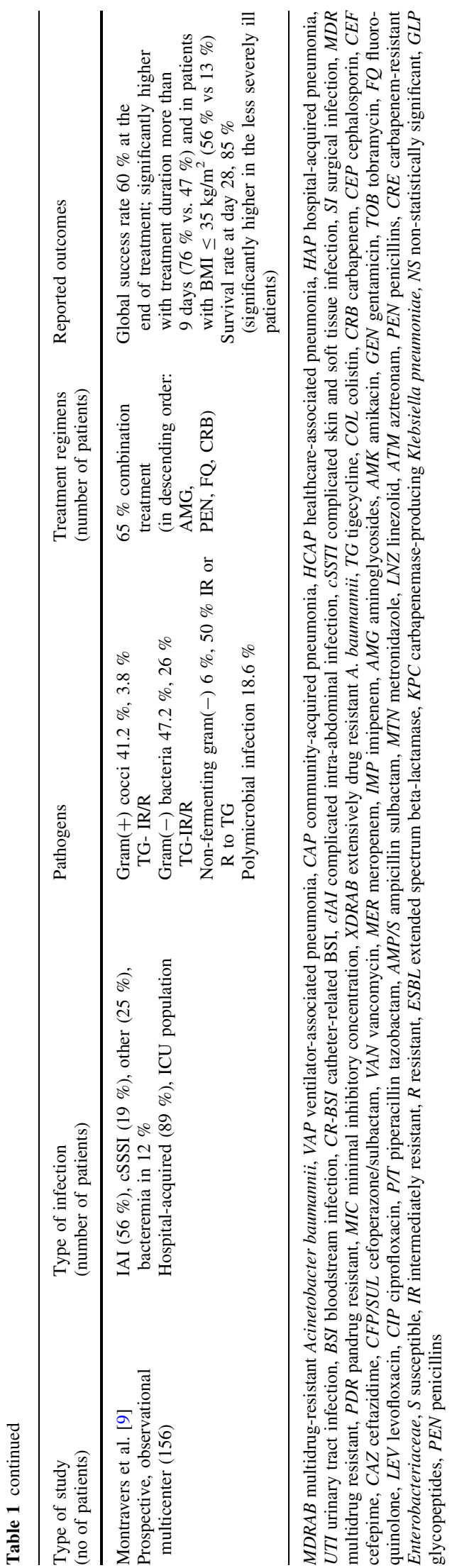

received tigecycline under real-life conditions of daily clinical practice. In this study tigecycline was used to treat a variety of infections, including some for which tigecycline was not granted approval for use, and the efficacy and safety profile support the use of this drug in complicated infections in critically ill patients [10]. Studies of clinical experience with tigecycline in nonapproved indications suffer significant heterogeneity and report a variety of clinical and microbiological endpoints with diverse rates of efficacy and mortality ranging from $12 \%$ to more than $80 \%$. In the majority of them, the true contribution of tigecycline to the outcome is confounded by the use of various combination regimens. These studies are summarised in Table 1.

Furthermore, recent published reports of infections caused by multidrug-resistant (MDR) pathogens with limited therapeutic options, including bacteria from the ESKAPE group, have highlighted an encouraging role of tigecycline in off-label use as part of a combination regimen. Specifically, tigecycline has been successfully used against life-threatening infections due to carbapenemase-producing Klebsiella pneumoniae (KPC) and MDR Acinetobacter baumannii in combination with other agents [11, 12]. In a large retrospective multicenter study significant reduction of 30-day mortality was demonstrated by logistic regression analysis when combination therapy (i.e., tigecycline, colistin, and meropenem) was used instead of monotherapy against KPC [12].

Almost 10 years after the launching of tigecycline, microbiological issues still exist. Although considerable in vitro activity has been shown for tigecycline against difficult-to-treat bacteria, the results are not universally consistent and may have varied according to different microbiological breakpoints. Furthermore, Vitek automated systems seem to overestimate resistance to $K$. pneumoniae $\mathrm{KPC}(+)$ strains, compared to E-test, therefore discouraging its use in a proportion of infections by almost untreatable pathogens [13]. In vitro interaction synergy studies against KPC or carbapenem-resistant Acinetobacter spp. have revealed promising effects of tigecycline in combination [14, 15]. Despite the demonstration of an adequate activity against Acinetobacter species of clinical significance [14], the question regarding whether tigecycline constitutes an effective option against resistant Acinetobacter spp. has not been comprehensively confirmed.

Another important issue is whether the dosage used so far was adequate from a PK/PD standpoint. A recent phase 2 study in HAP and VAP investigated the use of two high-dosage (HD) tigecycline regimens (200 mg initial, and then $100 \mathrm{mg}$ twice daily or $150 \mathrm{mg}$ initial and then $75 \mathrm{mg}$ twice daily) showing higher cure rates when the "highest" HD was used compared to lower dosage and imipenem/cilastatin 
[16]. The study hypothesized that a higher area under the concentration-time divided by the MIC (AUC/ MIC ratio) above one was necessary on the basis of a previous phase 3 study demonstrating lower cure rates in patients with HAP treated with conventional dose of tigecycline; this effect was attributed to a lower exposure to the drug on the lung tissue level [16]. This undermines the necessity of high doses when the MIC of the pathogen exceeds $0.5 \mathrm{mg} / \mathrm{L}$. Similarly, another study encompassing 100 ICU patients treated with either standard or HD tigecycline showed no differences in terms of ICU mortality but numerically higher clinical cure rate and microbiological eradication in the HD arm compared to the tigecycline standard dose group. In the multivariate model HD tigecycline was a predictor of clinical cure [36]. Furthermore, compared to colistin that did not reach sufficient drug levels in the lung tissue, HD tigecycline was efficacious for treating experimental pneumonia due to metallo-beta-lactamase (NDM-1)producing Enterobacteriaceae [17].

Although no major issues of toxicity have been displayed at high doses so far, the tolerability of these regimens in large trials still needs to be assessed [16] Finally, tigecycline's propensity to select for resistant strains (e.g., MDR Acinetobacter spp.) and to induce Pseudomonas aeruginosa or Proteus spp. superinfections requires further investigation.

In conclusion, despite the obscure vision provided by an impressive number of meta-analyses, tigecycline is expected to be used more often in approved indications and in off-label combination regimens for the treatment of MDR gram-negative infections in routine clinical practice. This is greatly supported by the large observational studies from five European countries and by the Montravers study mentioned above $[9,10]$. Well-controlled prospective studies are necessary to evaluate tigecycline's efficacy and safety profile at high doses.

The increased medical need represented by the growing impact of multiresistant infections and the current lack of alternative or new antibiotics suggests that tigecycline benefit-risk continues to be positive.

Conflicts of interest $\mathrm{MB}$ serves on scientific advisory boards and has received funding for travel or speaker honoraria from Pfizer Inc. The other authors declare no conflict of interest.

\section{References}

1. FDA (2010) FDA drug safety communication: increased risk of death with Tygacil (tigecycline) compared to other antibiotics used to treat similar infections.

http://www.fda.gov/Drugs/DrugSafety/ ucm 224370.htm. Accessed 28 April 2014

2. FDA (2013) FDA drug safety communication: FDA warns of increased risk of death with IV antibacterial Tygacil (tigecycline) and approves new boxed warning. http://www.fda.gov/drugs/drugsafety/ ucm369580.htm. Accessed 5 May 2014

3. Yahav D, Lador A, Paul M, Leibovici L (2011) Efficacy and safety of tigecycline: a systematic review and meta-analysis. J Antimicrob Chemother 66:1963-1971

4. Cai Y, Wang R, Liang B, Bai N, Liu Y (2011) Systematic review and metaanalysis of the effectiveness and safety of tigecycline for treatment of infectious disease. Antimicrob Agents Chemother 55:1162-1172

5. Tasina E, Haidich AB, Kokkali S, Arvanitidou M (2011) Efficacy and safety of tigecycline for the treatment of infectious diseases: a meta-analysis. Lancet Infect Dis 11:834-844
6. McGovern PC, Wible M, El-Tahtawy A, Biswas P, Meyer RD (2013) Allcause mortality imbalance in the tigecycline phase 3 and 4 clinical trials. Int J Antimicrob Agents 41:463-467

7. Vardakas KZ, Rafailidis PI, Falagas ME (2012) Effectiveness and safety of tigecycline: focus on use for approved indications. Clin Infect Dis 54:1672-1674

8. Prasad P, Sun J, Danner RL, Natanson C (2012) Excess deaths associated with tigecycline after approval based on non inferiority trials. Clin Infect Dis 54:1699-1709

9. Montravers P, Dupont H, Bedos J-P, Bret P, The Tigecycline Group (2014) Tigecycline use in critically ill patients: a multicentre prospective observational study in the intensive care setting. Intensive Care Med. doi: 10.1007/s00134-014-3323-7

10. Bassetti M, Eckmann C, Bodmann KF, Dupont H, Heizmann WR, Montravers P, Guirao X, Capparella MR, Simoneau D, Sanchez Garcia M (2013) Prescription behaviours for tigecycline in real-life clinical practice from five European observational studies. J Antimicrob Chemother 68(Suppl 2): $5-14$
11. Kontopidou F, Giamarellou H, Katerelos P, Maragos A, Kioumis I, Trikka-Graphakos E, Valakis C, Maltezou HC, Group for the Study of KPC-producing Klebsiella pneumoniae infections in intensive care units (2014) Infections caused by carbapenemresistant Klebsiella pneumoniae among patients in intensive care units in Greece: a multi-centre study on clinical outcome and therapeutic options. Clin Microbiol Infect 20:O117-O123

12. Tumbarello M, Viale P, Viscoli C, Trecarichi EM, Tumietto F, Marchese A, Spanu T, Ambretti S, Ginocchio F, Cristini F et al (2012) Predictors of mortality in bloodstream infections caused by Klebsiella pneumoniae carbapenemase-producing $K$. pneumoniae: importance of combination therapy. Clin Infect Dis 55:943-950

13. Zarkotou O, Pournaras S, Altouvas G, Pitiriga V, Tziraki M, Mamali V, Themeli-Digalaki K, Tsakris A (2012) Comparative evaluation of tigecycline susceptibility testing methods for expanded-spectrum cephalosporin- and carbapenem-resistant gram-negative pathogens. J Clin Microbiol 50:3747-3750 
14. Sheng WH, Wang JT, Li SY, Lin YC, Cheng A, Chen YC, Chang SC (2011) Comparative in vitro antimicrobial susceptibilities and synergistic activities of antimicrobial combinations against carbapenem-resistant Acinetobacter species: acinetobacter baumannii versus Acinetobacter genospecies 3 and 13TU. Diagn Microbiol Infect Dis 70:380-386

15. Peck KR, Kim MJ, Choi JY, Kim HS, Kang CI, Cho YK, Park DW, Lee HJ, Lee MS, Ko KS (2012) In vitro time-kill studies of antimicrobial agents against blood isolates of imipenem-resistant Acinetobacter baumannii, including colistin- or tigecycline-resistant isolates. J Med Microbiol 61:353-360

16. Ramirez J, Dartois N, Gandjini H, Yan JL, Korth-Bradley J, McGovern PC (2013) Randomized phase 2 trial to evaluate the clinical efficacy of two high-dosage tigecycline regimens versus imipenem-cilastatin for treatment of hospital-acquired pneumonia. Antimicrob Agents Chemother 57:1756-1762

17. De Pascale G, Montini L, Spanu T, Bernini V, Occhionero A, Grieco DL, Biancone M, De Santis P, Tanzarella ES, Cutuli SL et al (2013) High-dose tigecycline use in severe infections. Critical Care 17(Suppl 2):P80

18. Docobo-Pérez F, Nordmann P, Domínguez-Herrera J, López-Rojas R, Smani Y, Poirel L, Pachón J (2012) Efficacies of colistin and tigecycline in mice with experimental pneumonia due to NDM-1-producing strains of Klebsiella pneumoniae and Escherichia coli. Int $\mathbf{J}$ Antimicrob Agents 39:251-254

19. Schafer JJ, Goff DA, Stevenson KB, Mangino JE (2007) Early experience with tigecycline for ventilatorassociated pneumonia and bacteremia caused by multidrug-resistant Acinetobacter baumannii. Pharmacotherapy 27:980-987

20. Swoboda S, Ober M, Hainer C, Lichtenstern C, Seiler C, Wendt C, Hoppe-Tichy T, Büchler M, Weigand MA (2008) Tigecycline for the treatment of patients with severe sepsis or septic shock: a drug use evaluation in a surgical intensive care unit. J Antimicrob Chemother 61:729-733

21. Vasilev K, Reshedko G, Orasan R, Sanchez M, Teras J, Babinchak T, Dukart G, Cooper A, Dartois N, Gandjini H, 309 Study Group et al (2008) A phase 3, openlabel, non-comparative study of tigecycline in the treatment of patients with selected serious infections due to resistant gram-negative organisms including Enterobacter species, Acinetobacter baumannii and Klebsiella pneumoniae. J Antimicrob Chemother 62(Suppl 1):i29-i40
22. Anthony KB, Fishman NO, Linkin DR, Gasink LB, Edelstein PH, Lautenbach E (2008) Clinical and microbiological outcomes of serious infections with multidrug-resistant gram-negative organisms treated with tigecycline. Clin Infect Dis 46:567-570

23. Gallagher JC, Rouse HM (2008) Tigecycline for the treatment of Acinetobacter infections: a case series. Ann Pharmacother 42:1188-1194

24. Curcio D, Fernández F, Vergara J, Vazquez W, Luna CM (2009) Late onset ventilator-associated pneumonia due to multidrug-resistant Acinetobacter spp.: experience with tigecycline. J Chemother 21:58-62

25. Gordon NC, Wareham DW (2009) A review of clinical and microbiological outcomes following treatment of infections involving multidrug-resistant Acinetobacter baumannii with tigecycline. J Antimicrob Chemother 63:775-780

26. Poulakou G, Kontopidou FV, Paramythiotou E, Kompoti M, Katsiari M, Mainas E, Nicolaou C, Yphantis D, Antoniadou A, Trikka-Graphakos E et al (2009) Tigecycline in the treatment of infections from multi-drug resistant gram-negative pathogens. J Infect 58:273-284

27. Jamal W, Salama M, Dehrab N, Al Hashem G, Shahin M, Rotimi VO (2009) Role of tigecycline in the control of a carbapenem-resistant Acinetobacter baumannii outbreak in an intensive care unit. J Hosp Infect 72:234-242

28. Freire AT, Melnyk V, Kim MJ, Datsenko O, Dzyublik O, Glumcher F, Chuang YC, Maroko RT, Dukart G, Cooper CA, 311 Study Group et al (2010) Comparison of tigecycline with imipenem/cilastatin for the treatment of hospital-acquired pneumonia. Diagn Microbiol Infect Dis 68:140-151

29. Metan G, Alp E, Yildiz O, Percin D, Aygen B, Sumerkan B (2010) Clinical experience with tigecycline in the treatment of carbapenem-resistant Acinetobacter infections. J Chemother 22:110-114

30. Kuo SC, Wang FD, Fung CP, Chen LY, Chen SJ, Chiang MC, Hsu SF, Liu CY (2011) Clinical experience with tigecycline as treatment for serious infections in elderly and critically ill patients. J Microbiol Immunol Infect $44: 45-51$
31. Ye JJ, Lin HS, Kuo AJ, Leu HS, Chiang PC, Huang CT, Lee MH (2011) The clinical implication and prognostic predictors of tigecycline treatment for pneumonia involving multidrugresistant Acinetobacter baumannii. J Infect 63:351-361

32. Guner R, Hasanoglu I, Keske S, Kalem AK, Tasyaran MA (2011) Outcomes in patients infected with carbapenemresistant Acinetobacter baumannii and treated with tigecycline alone or in combination therapy. Infection 39:515-518

33. $\mathrm{Ku} \mathrm{K}$, Pogue JM, Moshos J, Bheemreddy S, Wang Y, Bhargava A, Campbell M, Khandker N, Lephart PR, Chopra T et al (2012) Retrospective evaluation of colistin versus tigecycline for the treatment of Acinetobacter baumannii and/or carbapenem-resistant Enterobacteriaceae infections. Am J Infect Control 40:983-987

34. Moon SY, Peck KR, Chang HH, Kim SW, Heo ST, Son JS, Ryu SY, Moon C, Jung SI, Shin SY et al (2012) Clinical experience of tigecycline treatment in infections caused by extensively drugresistant Acinetobacter spp. Microb Drug Resist 18:562-566

35. Kim NH, Hwang JH, Song KH, Choe PG, Kim ES, Park SW, Kim HB, Kim NJ, Park WB, Oh MD (2013) Tigecycline in carbapenem-resistant Acinetobacter baumannii bacteraemia: susceptibility and clinical outcome. Scand J Infect Dis 45:315-319

36. Lee YT, Tsao SM, Hsueh PR (2013) Clinical outcomes of tigecycline alone or in combination with other antimicrobial agents for the treatment of patients with healthcare-associated multidrug-resistant Acinetobacter baumannii infections. Eur J Clin Microbiol Infect Dis 32:1211-1220

37. Chuang YC, Cheng CY, Sheng WH, Sun HY, Wang JT, Chen YC, Chang SC (2014) Effectiveness of tigecyclinebased versus colistin-based therapy for treatment of pneumonia caused by multidrug-resistant Acinetobacter baumannii in a critical setting: a matched cohort analysis. BMC Infect Dis 14:102 